Article

\title{
Knowledge-Based Estimation of Edible Fern Harvesting Sites in Mountainous Communities of Northeastern Japan
}

\author{
Toshiya Matsuura $^{1, *}$, Ken Sugimura ${ }^{2}$, Asako Miyamoto ${ }^{1}$ and Nobuhiko Tanaka ${ }^{3}$ \\ 1 Department of Forest Management, Forestry and Forest Products Research Institute, 1 Matsunosato, \\ Tsukuba, Ibaraki 305-8687, Japan; E-Mail: asakom@affrc.go.jp \\ 2 Research Planning and Coordination Department, Forestry and Forest Products Research Institute, \\ 1 Matsunosato, Tsukuba, Ibaraki 305-8687, Japan; E-Mail: kensugi@affrc.go.jp \\ 3 School of Tourism, Tokai University, 2-28-4 Tomigaya, Shibuya-ku, Tokyo 151-8677, Japan; \\ E-Mail: tanaka_nobuhiko@tokai-u.jp
}

* Author to whom correspondence should be addressed; E-Mail: matsuu50@affrc.go.jp; Tel.: +81-29-829-8314; Fax: +81-29-873-3799.

Received: 11 October 2013; in revised form: 25 November 2013 / Accepted: 18 December 2013 / Published: 27 December 2013

\begin{abstract}
Once local expert knowledge regarding the harvesting of various non-timber forest products (NTFPs) is lost, it is difficult to recover. We investigated whether the knowledge of expert forest harvesters can be used to determine the habitat distribution and harvesting sites of three popular edible wild ferns, i.e., ostrich fern (Matteuccia struthiopteris), bracken (Pteridium aquilinum), and royal fern (Osmunda japonica), in mountainous communities of western Fukushima, Japan. Using multi-criteria evaluation (MCE) based on the analytic hierarchy process (AHP) and geographic information system (GIS), we found that harvesters were easily able to recognize differences in the spatial characteristics of the habitat distribution of fern species due to both natural and anthropogenic factors. These factors were described by various GIS layers, such as vegetation and terrain features (e.g., gradient, aspect, and slope position) derived from a 20-m digital elevation model (DEM). Harvesting sites were limited by their distance from a roadway, which differed among species. By comparison with the GPS records of actual harvesting sites, we estimated the potential harvesting sites of each fern species with reasonable accuracy, particularly for bracken. Our results show that the knowledge of expert forest harvesters can be quantified using MCE and GIS, which is useful for determining the spatial characteristics of NTFP harvesting and ensuring sustainable management practices.
\end{abstract}


Keywords: multi-criteria evaluation; GIS; AHP; NTFP; ecosystem services; Fukushima Prefecture

\section{Introduction}

Rural forest communities have long been dependent on a variety of ecosystem goods and services, and many individuals living in such communities have a rich empirical knowledge of the use of the local environment and its biodiversity [1-4]. A typical example is the use of non-timber forest products (NTFPs), which can be categorized into biodiversity-based provisioning and cultural services [5-7]. Sustainable harvesting has been intensively analyzed in terms of its socioeconomic and political aspects [8,9], as well as the ecological effects of different types, intensity, and timing of harvesting [10-12]. Local people generally harvest various NTFP species; however relatively few studies have investigated the spatial differences in harvesting sites among species, which is critical for their sustainable use, possibly due to the limited habitat requirements of some species in heterogeneous landscapes [13].

In recent decades, many studies have shown that expert knowledge can be used in habitat suitability mapping and forest landscape management [14-16]. One of the most popularly used models is multi-criteria evaluation (MCE) based on the analytic hierarchy process (AHP) and geographic information system (GIS) [17-21]. Once a knowledge-based model is developed for a species, its potential distribution can easily be estimated over a large area. Because forest-related indigenous knowledge has been disappearing both in developed and developing countries [22], a specific methodology that can integrate such knowledge into spatially explicit models is urgently required. However, few studies have investigated the harvesting sites of NTFPs based on the knowledge of local experts. One notable exception is Yang et al. (2006), who determined the harvesting sites of edible mushrooms [23]. In addition, few studies have considered how large the harvesting site of a species is in relation to its habitat distribution. This distinction is important regarding sustainable resource use because it compares the sites under harvesting pressure and the area of availability, which may vary among species.

In Japan, a variety of edible wild plants are harvested annually, particularly in the northeastern archipelago where cool-temperate forests dominate [24-28]. Although the frequency and amount of harvesting has been declining for several reasons including an aging society, depopulation in mountain villages, and changes in eating habits, sustainability is locally suspected for some species and is not negligible in terms of household consumption and as an additional income source for the residents of rural areas [29]. Wild plants also attract harvesters from large cities [28,30].

In the present study, we investigated whether the local knowledge of forest harvesters could be used to determine potential harvesting sites for three of the most popular edible ferns, i.e., ostrich fern (Matteuccia struthiopteris), bracken (Pteridium aquilinum), and royal fern (Osmunda japonica) using MCE and GIS. We hypothesized that local inhabitants would clearly recognize the differences in harvesting sites among fern species due to both environmental and anthropogenic factors. We discuss the characteristics of these models and their applicability for spatial characterization and mapping of the provisioning services of NTFP harvests and for their sustainable resource management. 


\section{Data and Methods}

\subsection{Study Area}

The study area $\left(56 \mathrm{~km}^{2}\right.$; approximately $\left.37^{\circ} 17^{\prime}-37^{\circ} 22^{\prime} \mathrm{N}, 139^{\circ} 28^{\prime}-139^{\circ} 34^{\prime} \mathrm{E}\right)$ was located in Tadami Town in the western Fukushima Prefecture of northeastern Japan, where over $90 \%$ of the land cover is forest (Figure 1). This area includes two rural communities (107 households in total) located along the main valley floor. This is a catchment area inclining from east to west with the elevation ranging from 460 to $960 \mathrm{~m}$. We selected this area because the harvesting of edible wild plants including the three fern species has been traditionally conducted and is still common [17]. This area is located in a cool-temperate region that experiences snow cover for almost half of the year (i.e., from November to early May), with a maximum snow depth of 2 to $4 \mathrm{~m}$. Due to the heavy snow in winter, there is a unique mosaic of forests and scrublands in this area [31,32]. Old-growth beech (Fagus crenata) forests largely dominate on the slopes, whereas snow avalanche scrubs (e.g., Quercus crispula, Clethra barbinervis) are distributed on the steep slopes. Five-needle pine (Pinus parviflora) forests are located on sharp ridges. Coppice oak forests (e.g., Quercus crispula and Quercus serrata) and conifer plantation forests, mainly Japanese cedar (Cryptomeria japonica) with some larch (Larix kaempferi) plantations, are found near roads and settlements. Residents of the communities gather a variety of edible wild plants after the snowmelt at the end of April until the middle of July. Harvesting by outsiders is permitted if a daily entrance fee is paid.

Figure 1. Study area.

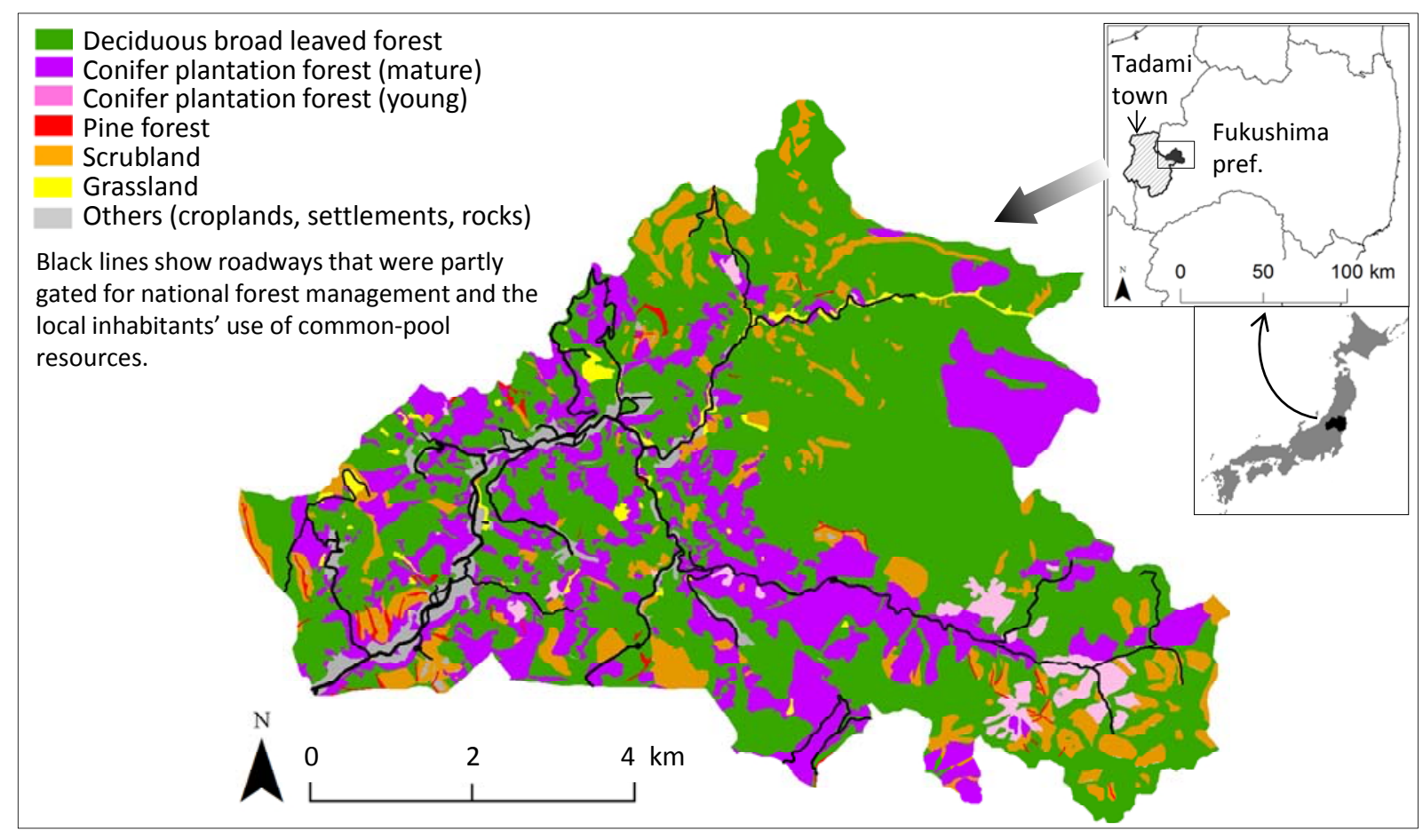

\subsection{Target Fern Species}

We investigated the harvesting sites of the three aforementioned ferns, all of which are summer-green ferns native to Japan $[33,34]$. Ostrich fern is widely distributed in cool-temperate regions in the 
Northern Hemisphere, in areas with rich and moist soils often on fluvial deposits [35]. Its fiddlehead has been used as a popular wild vegetable in North America and northeastern Japan [36]. Bracken is distributed worldwide, except in very cold or dry conditions and has become dominant in some grasslands [37,38]. Although it has deleterious effects on animals such as cattle and also on human health [39], its first sprouting is an important food item in East Asia, including Korea and Japan [40-42]. This is because its carcinogenic contents can be largely removed by boiling the harvested sprouts in water with wood ash or sodium bicarbonate [43]. Osmunda japonica is biologically similar to Osmunda regalis, which is distributed worldwide [44]. The first sprouting of this fern has been commonly eaten in East Asia. This fern has been commonly used as a sun-dried preserved mountain vegetable in Japan, and is produced by a three-day process of boiling, drying, and squeezing by hand [25]. Although these three ferns are common species, sustainable harvesting is still an important issue because harvesting activities are generally allowed in a limited area near each settlement, with the areas serving as common-pool resources for local residents in the study communities [25].

\subsection{GIS Data Set}

Based on interviews with experienced harvesters in the study area, we identified three groups of factors that were related to the spatial distribution of harvesting sites of the ferns that could be easily mapped in GIS, i.e., vegetation, terrain features, and accessibility from roadways (Table 1). We assumed that other important factors such as soils, humidity, and microclimatic conditions could be approximated from vegetation and terrain features. We digitized a 1:25,000 physiognomic vegetation map produced by the interpretation of aerial photographs taken between 1978 and 1980, with ancillary fieldwork by the Board of Education in Tadami Town [45]. We significantly updated this map, particularly the clear-cut or afforested areas (mainly Japanese cedar with some larch plantations) by interpreting aerial photos taken in 2004 and 2009, and 1:50,000 forest planning maps published by the Forestry Agency and Fukushima Prefecture in 2006. Conifer plantation forest was classified as young or mature 20 years after planting, because canopy openings with brighter light conditions in the understory still dominate until around this age due mainly to the heavy snow conditions. The polygon map was further converted into a $20 \mathrm{~m}$ grid raster by overlaying with a 20 -m digital elevation model (DEM). The six dominant vegetation classes used in this study were deciduous broadleaved forest, conifer plantation (mature), conifer plantation (young), pine forest, scrubland, and grassland (see Figure 1). Terrain features such as gradient, aspect, and relative slope position were generated from a $20 \mathrm{~m}$ DEM, which was interpolated from the 10-m interval contours of 1:25,000 topographic maps published by the Geospatial Information Authority of Japan. Details of each terrain feature are shown in Table 1. We computed the proximity to forestry paths or roadways using path distance, i.e., the shortest distance on the surface, which is longer than the horizontal distance on slopes. To describe the difficulty accessing steep slopes such as snow avalanches and cliffs, we added costs of walking on steeper slopes using a symmetric inverse linear function with a maximum absolute gradient of 60 degrees based on the ArcGIS 10.1 Spatial Analyst extension. We further estimated the access time $t=d / v$, where path distance $d$ was divided by the average walking velocity $v$ on a flat plain. Average velocities of 2,3 , and $4 \mathrm{~km} / \mathrm{h}$ were used for comparison. 
Table 1. Variables used for the multi-criteria evaluation (MCE).

\begin{tabular}{|c|c|c|c|c|c|c|}
\hline $\begin{array}{c}\text { Explanatory } \\
\text { Variables } \\
\end{array}$ & Description & Min & Max & Mean & Std. Dev. & Unit \\
\hline Vegetation & $\begin{array}{l}\text { Vegetation classes: deciduous broadleaved } \\
\text { forest, young and mature conifer plantations, } \\
\text { pine forest, scrubland, and grassland. }\end{array}$ & \multicolumn{4}{|c|}{ (binary) } & - \\
\hline \multicolumn{7}{|c|}{ Terrain features derived from a $20-\mathrm{m} \mathrm{DEM}^{\mathrm{a}}$} \\
\hline Gradient & $\begin{array}{l}\text { Gradient measured as the maximum rate of } \\
\text { change in surface elevation between each } \\
\text { cell and its neighbors. }\end{array}$ & 0.06 & 54.68 & 21.41 & 8.63 & degrees \\
\hline Aspect & Aspect measured clockwise from north. & 0 & 360 & 184.7 & 103.7 & degrees \\
\hline $\begin{array}{l}\text { Relative } \\
\text { slope position }\end{array}$ & $\begin{array}{l}\text { Relative slope position was measured by the } \\
\text { height from the nearest drainage line to each } \\
\text { grid point [46] divided by the vertical size of } \\
\text { a side slope profile, i.e., height between the } \\
\text { nearest drainage and ridge lines. }\end{array}$ & 0 & 1 & 0.63 & 0.33 & - \\
\hline $\begin{array}{l}\text { Proximity } \\
\text { to roads }\end{array}$ & $\begin{array}{l}\text { Path distance to the nearest roadway on a } \\
20 \text {-m DEM. Inverse distance weighting up to } \\
60 \text { degrees in both upslope and down slope } \\
\text { directions was applied. }\end{array}$ & 0 & 2538.6 & 652.3 & 542.4 & $\mathrm{~m}$ \\
\hline
\end{tabular}

${ }^{a}$ ArcGIS spatial analyst was used.

\section{4. $M C E$}

To analyze the spatial characteristics of the fern-harvesting sites, we used MCE based on AHP and GIS. Using a questionnaire, a group interview to determine scoring factors in the AHP framework (Figure 2) was held in July and August, 2009, with four experienced harvesters (males, ages from 65 to 70) in the study communities. All of them were pensioners in different households, who had retired from local government, factory, or forestry jobs. We selected them as respondents because they had a long experience of harvesting wild plants, beginning in their childhood and were also forest tourism guides in the community with a good knowledge of various local forest uses. In addition, the majority of harvesters currently living in the villages were from this generation and were males aged in their 60 s to 70s [29]. Wild plants are mainly harvested for household consumption but also for private sales or as presents for friends and relatives. Two of them also had contracts to harvest bracken in grassland managed by a company processing edible wild plants that was supported by the town.

Using the questionnaire, we determined the relative importance between factors of terrain features and vegetation and among terrain features (i.e., gradient, aspect, and slope position). Because there were too many pairwise comparisons to determine the relative importance among classes within each factor (i.e., vegetation, gradient, aspect, slope position, and proximity to roads; see Figure 2), we first asked questions that enable us to rank the intensity of importance of each class into nine grades and then compared the scores among classes to fit in the AHP framework. Because the recognition of suitable harvesting sites may differ among harvesters, an agreed score was recorded after a group discussion among the respondents. 
Figure 2. Analytic hierarchy process (AHP) dendrogram describing the harvest sites of edible wild ferns.

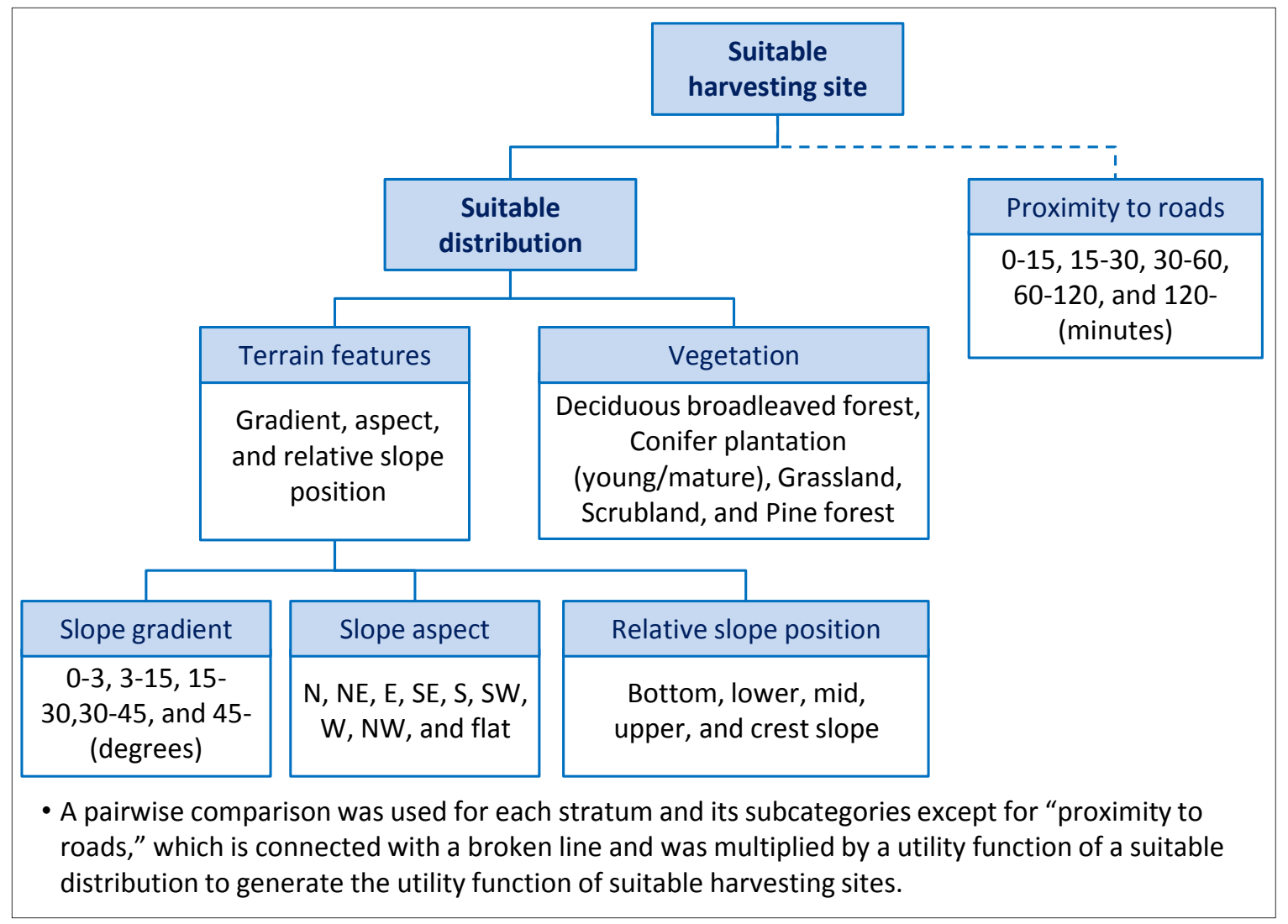

In the MCE framework with GIS layers, a utility is described as an additive utility function $U[17,47]$ :

$$
U=\sum a_{i} u_{i}
$$

where $u_{i}$ is a partial utility function of factor $i$ with a weighting $a_{i}$, i.e., AHP scores, which numerically determine the relative importance of factors based on a pairwise comparison of each level of hierarchy of the factors [48]. For constructing a pairwise comparison matrix, each factor is rated against every other factor by assigning values of the intensity of importance between 1 and 9 and their reciprocals [48-50]. The importance in each location for each GIS layer was described using the following equations:

$$
\begin{gathered}
u_{i}=b_{i}\left(g_{i}\right) \\
b_{i}=c_{i} / \max (c)
\end{gathered}
$$

where $b_{i}$ is the standardized AHP score of factor $i$ in a GIS layer $g$ (ranging from 0 to 1 ), divided by the maximum score among alternative criteria $c_{i}$ [47].

The potential distribution of an edible wild fern $U_{d}$ was estimated using the following additive equations:

$$
\begin{gathered}
U_{d}=a_{t} u_{t}+a_{v} u_{v} \\
u_{t}=a_{g} u_{g}+a_{a} u_{a}+a_{s} u_{s}
\end{gathered}
$$


where $u_{t}$ and $u_{v}$ are partial utility functions of terrain features and vegetation, respectively, with weightings, $a_{t}$ and $a_{v}$, i.e., AHP scores. The partial utility function of terrain features $u_{t}$ was generated from the partial utility functions of the gradient, aspect, and slope position, i.e., $u_{g}, u_{a}$, and $u_{s}$, respectively, with their weightings $a_{g}, a_{a}$, and $a_{s}$. The partial utility functions of $u_{g}, u_{a}, u_{s}$, and $u_{v}$ were generated from GIS layers and AHP scores as shown in Equations (2) and (3). For the GIS layers with continuous values (i.e., gradient, aspect, and slope position), the minimum, maximum, and several intermediate values (see Figure 2) were compared and then the standardized AHP scores were linearly interpolated to generate continuous relationships [17,51].

Then potential harvesting areas were estimated by multiplying the utility functions of the edible fern distribution $U_{d}$ by a utility function for the proximity to roads $u_{p}$ as follows:

$$
\begin{gathered}
U_{h}=U_{d} \times u_{p} \\
u_{p}=b_{p}\left(g_{p}\right)
\end{gathered}
$$

where $b_{p}$ is the AHP score of a GIS layer $g_{p}$, i.e., proximity to roads. Multiplication was used in Equation (6) because the importance of accessibility cannot be compared to other site factors. Even in areas with a large potential distribution, it is difficult to harvest if the area is difficult to access.

\subsection{Model Verification}

For verification, we checked the correspondences between the estimated and actual harvesting sites of each fern species. Actual harvesting sites were recorded by each harvester during the harvesting season from May to July 2009 using small GPS devices that were placed into a cap. The harvesting areas of each fern species were delimited by removing erroneous GPS points using the kernel density function in Geospatial Modelling Environment (GME ver. 0.7.2.1) [52], while non-harvesting sites were determined for the rest of the study area, except for the harvesting sites and their surroundings using $100 \mathrm{~m}$ radius buffers. Some of the harvesting sites were determined by ancillary interviews with harvesters. Then equally stratified random sampling [53] was used to obtain an equal number of harvesting/non-harvesting samples (i.e., 300 samples each) for each fern species. We conducted this sampling 10 times to obtain robust verification results. We computed the area under the receiver operating characteristic (ROC) curve (AUC), which provided a single measure of the overall accuracy, ranging from 0.5 to 1.0 , that was not dependent on a particular threshold value $[54,55]$. The kappa index was also generated from the ROC curve using a cutoff value where the kappa value was maximized [56].

\section{Results}

Gatherers place different priorities on the harvesting sites for each fern species. The relative importance of terrain features and vegetation is summarized in Figure 3. Terrain features were considered to be more important than vegetation for harvesting ostrich fern and royal fern, and vice versa for bracken. Slope position was more important than gradient for harvesting ostrich fern and bracken, whereas for royal fern, slope aspect and gradient were more important than slope position. Slope aspect was recognized to be important only for royal fern. 
Figure 3. Results of AHP for the pairwise comparison of (A) vegetation vs. terrain features, and (B) among terrain features. Figures in parentheses show the consistency index.

(A)

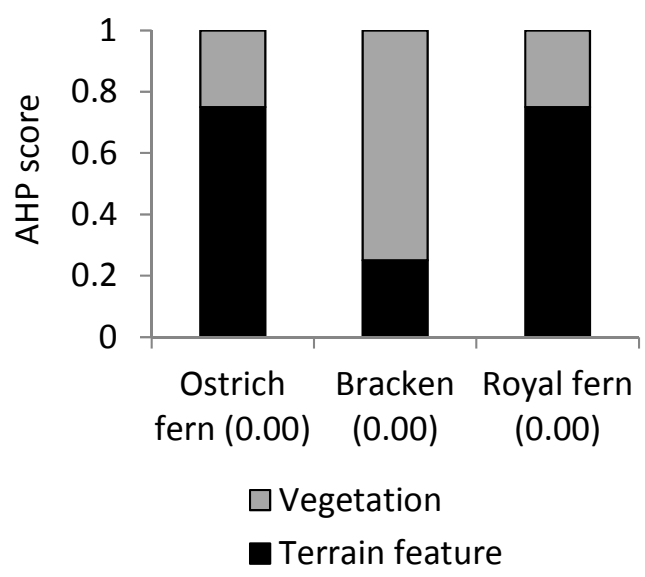

(B)

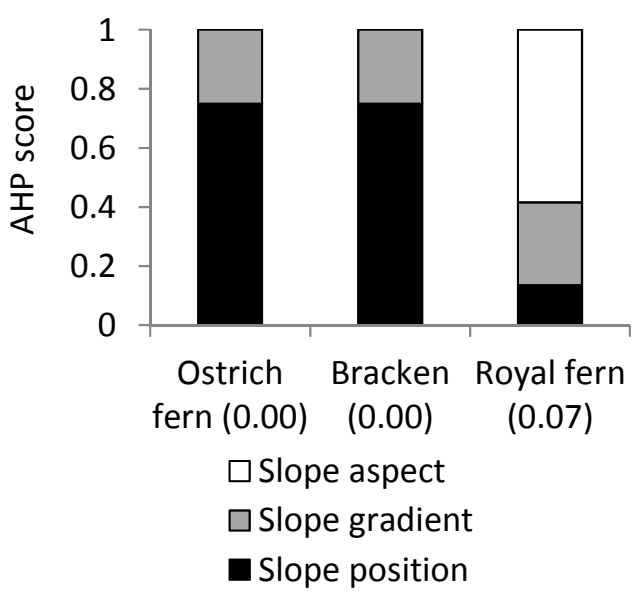

Figure 4 shows the partial utility function of each GIS layer. For ostrich fern, grassland was considered to be the most important vegetation class followed by scrubland and deciduous broadleaved forest (see Figure 4A). For royal fern, scrubland was the most important vegetation class followed by deciduous broadleaved forest. For bracken, the most important vegetation class was grassland, followed by young conifer plantation. We also found clear differences among the ferns in terms of slope gradient and slope position (see Figure 4B,C), with gatherers recognizing that more ostrich fern could be harvested on gentler slopes, e.g., those located near valley floors and alluvial cones. Conversely, royal fern could be harvested more readily on the steeper surfaces that were typically found on the snow avalanche slopes. In contrast to the other two fern species, harvesters recognized that bracken could be harvested almost anywhere from the lower to the upper part of the slopes. Harvesters recognized that northeast facing slopes were the best for harvesting royal ferns, while slope aspect was not selected as an important factor for the other two ferns (see Figure 4D). With regard to the proximity to roads, harvesters spent more time accessing the gathering sites of royal ferns, followed by bracken and ostrich fern (see Figure 4E).

We estimated the potential habitat distribution of each fern species based on the additive utility functions of vegetation and terrain features (Figure 5A-C), then potential harvesting sites were determined by multiplying with the utility function of proximity to roadways (Figure 5D-F). Suitable landscape features were clearly different among the three fern species. Potential harvesting sites of ostrich fern were limited in riparian areas such as valley floors and foot slopes (see Figure 5D). Bracken harvesting sites were likely to be distributed in grassland, scrubland, and cedar plantations where human-induced disturbances were present and clear cutting and plantation forestry dominated (see Figure 5E). Royal fern tended to be harvested most on steep northeast-facing slopes that were frequently covered by snow avalanche scrublands (see Figure 5F). Because ostrich fern and bracken were likely to be harvested near roadways compared to royal fern (see Figure 4E), their potential harvesting sites were more limited than those of royal fern (see Figure 5D-F). 
Figure 4. Partial utility functions estimated from AHP for geographic information system (GIS) layers: (A) vegetation classes, (B) gradient, (C) slope position, (D) aspect, and (E) proximity to roads. The $\mathrm{x}$-axis indicates each GIS layer value and the y-axis shows the AHP score standardized by its maximum value.

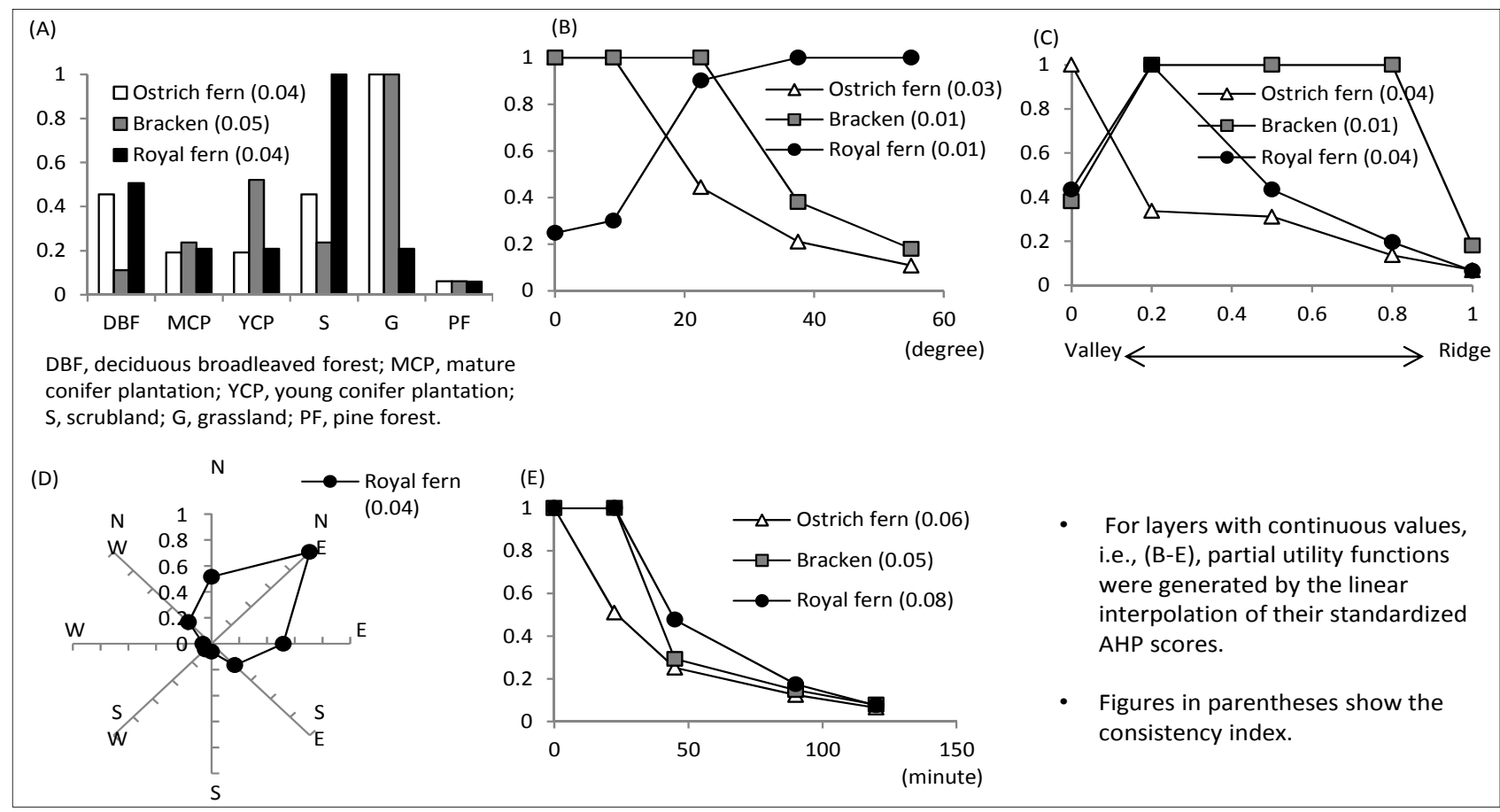

Figure 5. Estimated potential habitat distribution and harvesting sites of ferns based on MCE.

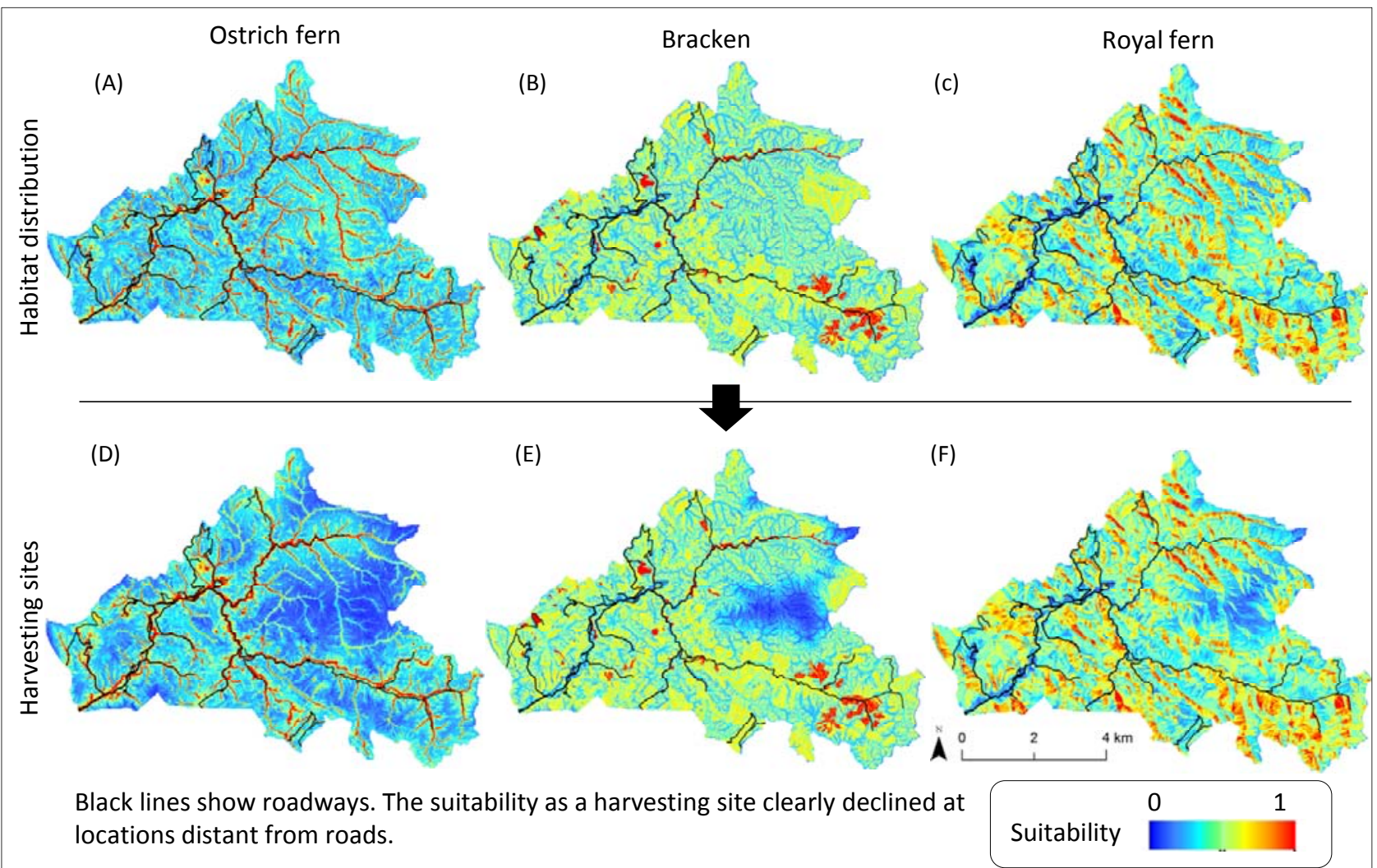


The verification results of the MCEs with different average walk velocities that were used for computing the time taken to access harvesting sites from the nearest roads are summarized in Figure 6. Among the three fern species, the accuracy of estimation for bracken was consistently the highest followed by ostrich fern and royal fern. AUC values ranged from 0.7 to 0.9 , which can be considered reasonable [57]. Kappa statistics are conventionally interpreted as slight to fair (0.0-0.4), moderate (0.4-0.6), substantial (0.6-0.8), and almost perfect (0.8-1.0) discriminations [55]. Based on this criterion, moderate levels of accuracy were obtained for most of the models, with the exception of the low level of accuracy for royal fern at the average velocities of 2 and $3 \mathrm{~km} / \mathrm{h}$.

Figure 6. Model accuracy.

(A)

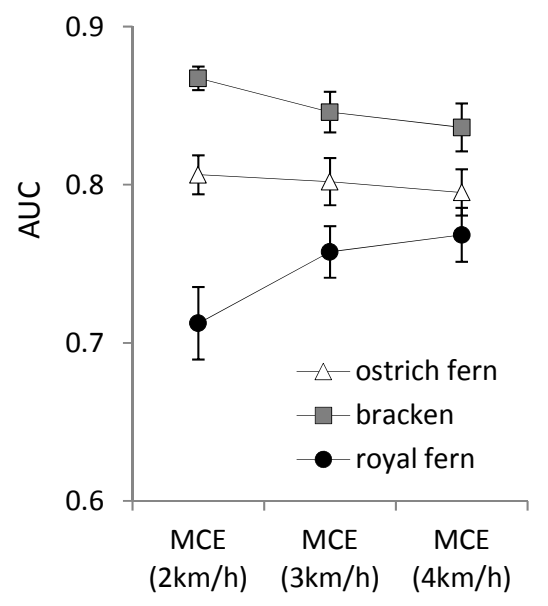

(B)

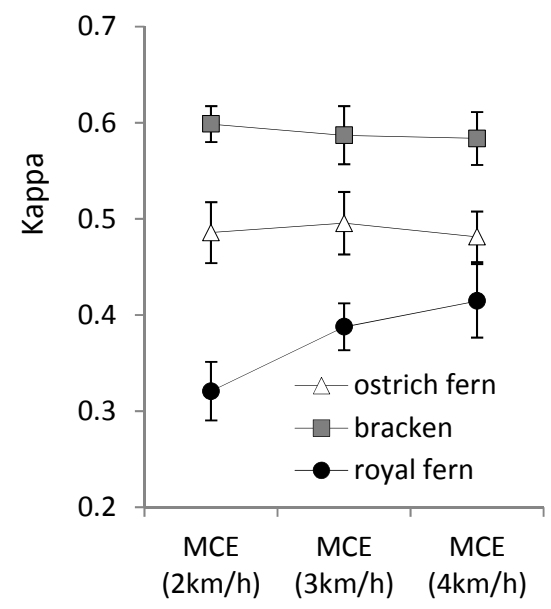

- Each point indicates the average value and error bars show the standard deviation ( $n=10$ for each species).

\section{Discussion}

Although the spatial characteristics of habitat distribution and the harvesting sites of a variety of NTFPs have been empirically described in many documents and guidebooks [34,58,59]; few studies have considered the effectiveness of using the knowledge of local experts and GIS for their determinations [23]. This study demonstrated the possibility of using such knowledge for the harvesting of the three most popular edible ferns in northeastern Japan. Our results clearly illustrate the spatial differences in both habitat distribution and harvesting sites among the fern species. The knowledge of local experts generally corresponded well with the empirical descriptions in previously published guidebooks of edible wild plants in Japan [58,60] with some local specifications in snowy mountainous villages.

Suitable habitats for ostrich fern were considered to be mainly in grasslands or canopy openings in gently sloping valley floors or alluvial cones, where moist fluvial sediments had accumulated [35]. Such landscapes are generally maintained by riparian disturbances of sediment $[61,62]$. Abandoned paddy fields or croplands in such landscapes were also recognized as suitable harvesting sites for ostrich fern. Suitable habitats for bracken were considered to be mainly deforested land or young conifer plantations that were often found on gentle slopes. This is because bracken can generally survive in and dominate such landscapes under conditions with strong human disturbances due to its tolerance of 
clear cutting and burning $[37,63]$. Because bracken often dominates in the understory of young cedar plantations [64], some researchers have proposed the joint agroforestry management of bracken and cedar plantations to provide additional income sources in mountain villages [65]. Suitable habitats for royal fern were considered to be the lower sides of steep northeast-facing slopes covered by scrublands. This is the leeward side of the strong winter monsoon from the Sea of Japan, which produces heavy snowfalls and allows snow avalanche scrublands to dominate [66,67]. Such landscapes are considered good harvesting sites for royal fern in snowy mountains because a humid environment with rich soil organic matter is maintained annually during the snowmelt season [45].

The additional criteria of accessibility to roadways also indicated some differences among the harvesting sites of fern species due mainly to the differences in their habitat distribution. Royal fern harvesting sites within snow avalanche scrublands were widely distributed in the study area, whereas canopy openings or abandoned paddies or croplands suitable for harvesting ostrich fern were mainly distributed in nearby valleys where road networks were likely to be located due to the absence of steep slopes. Deforested areas and young conifer plantations that were suitable as bracken-harvesting sites were mainly located near roads. Model accuracies differed with the different average walking velocities (see Figure 6). Therefore, it would be reasonable to assume that this is due to the difference in harvesting styles among fern species. Based on our field observations, harvesters often walked straight to the harvesting sites of royal ferns away from the roads, whereas for ostrich fern and bracken, they generally start harvesting close to the roads on the way to harvesting sites.

We estimated harvesting sites more accurately for bracken than the other two ferns (see Figure 6). This is mainly because the harvesting sites of bracken were largely limited to grasslands or young conifer plantations, whereas those of the other ferns were scattered over the study area, e.g., canopy openings along riparian areas for ostrich fern and snow avalanche scrublands for royal fern.

We found that harvesters considered both canopy and terrain features when determining the likely habitat distribution of ferns. The slope position was particularly important for the distribution of ostrich fern in riparian areas where there were many small canopy gaps or openings due to riparian disturbances. We also found that harvesters were aware of the importance of past land use/management (e.g., clear-cutting, mowing, reforestation) in determining the harvesting sites of ferns, particularly for bracken. Several ecological studies have also documented the importance of terrain features [68-70] and the land use/management history [71] to the distribution of understory flora such as ferns; however, the effectiveness of local expert knowledge has seldom been examined quantitatively. Our results indicate that expert knowledge could be used to describe the spatial characteristics of habitat distribution and harvesting sites for different fern species based on MCE and GIS.

This study identified the differences between the habitat distribution and harvesting sites of the three fern species using distance from roads (see Figure 5). This is important for the sustainability of ferns because not all of the fern habitats are used as harvesting sites. The farther that a fern habitat is from a road, the lower the harvesting pressure becomes. This varies among species as well as with harvesting intensity. In addition, according to our observation, local harvesters generally leave part of the first sprouting or fiddleheads in each fern crown to ensure the sustainability of the harvesting sites. However, the estimated habitat distributions might be too limited compared to their actual distributions because the smaller fronds of royal ferns are sparsely distributed even under dense forest canopies [72] 
and are not attractive for harvesters. Further studies that compare actual habitat distributions based on a field survey would reveal the key factors for sustainable harvesting.

This study estimated the potential harvesting sites of ferns with reasonable accuracy based on a group interview with only four expert harvesters, suggesting that it is important to select representative informants who have a rich knowledge of NTFP harvesting to develop reliable models. Because we conducted a group interview, the results might have been partly influenced by the stronger opinions among harvesters. However, we observed in most cases, that the spatial characteristics of the harvesting sites agreed among the informants during their group discussion. This knowledge may have been improved through communication with each other. Alternatively, our results might be biased due to the sampling of only male harvesters aged from the mid-60s to early 70 s, who are currently the main harvesters in the village [29]. Younger generations are generally less interested in or cannot commit their time to harvest ferns in the wild, and their inclusion would not be very likely to affect the results. Female harvesters generally use sites nearer to roads and settlements than male harvesters [29]; therefore, harvesting sites close to roads and settlements might be more important than our results indicate. People in these communities harvested farther away from roads and settlements than they currently do until 1980s, when the harvesting of wild plants was part of the livelihood even for younger generations and was more competitive than at present [25]. Therefore, if the attributes of the main harvesters change, the composition of the interviewees should be altered accordingly.

Yang et al. (2006) [23] compared the use of a statistical model (i.e., logistic regression) and a knowledge-based model for estimating the habitat distribution of matsutake mushrooms (Tricholoma spp.) in Yunnan Province of China and revealed that similar results could be obtained from both of them, although the knowledge-based model was superior due to its lower data requirements. In addition, knowledge-based models can be applicable to the distribution of some species that are difficult to survey including historical distributions or others with high levels of uncertainty; hence, we used MCE and obtained reasonable levels of accuracy. Although it is beyond the scope of this study, a comparison between the two models would also be informative because the appropriate model to use would also depend on species characteristics.

Based on a sensitivity analysis of each explanatory variable, it would be further possible to estimate the effects of environmental changes on the results [17]. For example, the enlargement of the forest clear-cutting area would increase the potential harvesting sites of bracken, while it may destroy those of ostrich fern along riparian areas. Construction of roads would increase the accessibility to harvesting sites to a different extent among the fern species, which would be good for the ease of harvesting but may increase the risk of overharvesting [73]. Conversely, if the maintenance of roads is insufficient, the potential harvesting area will become smaller but more habitats would be conserved. The number of accessible harvesting areas might also change if the number of active harvesters and their frequency of harvesting increases/decreases due to changes in the population or in market conditions, particularly for commercially harvested species [73]. Such future scenario-based estimations would be useful for predicting future changes in the harvesting of NTFPs and contribute to their management.

This study demonstrated a procedure to quantitatively summarize the local expert knowledge of NTFP harvesting into utility functions that can be used to estimate the potential distribution of habitats and harvesting sites, which have rarely been mapped explicitly. This is important because the spatial characteristics of habitats and harvesting sites of NTFP species can be quantitatively expressed based 
on the limited expert knowledge using widely available GIS layers of vegetation (land cover), DEM, and road networks, more easily than obtaining original field data. The results are useful for identifying species with spatially restricted habitats and their harvesting sites under different natural and/or anthropogenic disturbance regimes as well as different harvesting pressures due mainly to the distance from roads [73]. Furthermore, the results are comparable to the distribution of other resources such as timber. As mentioned previously, some species respond positively to forest clear-cutting (e.g., bracken), while others do not. Positive/negative effects of forestry activities on habitats and harvesting sites of NTFP species have also been reported in other regions of the world [74,75]. Using the models currently available, we can estimate the possible effects of various activities such as forestry (e.g., logging, reforestation, and construction/management of logging roads) and agriculture (e.g., cropland development/abandonment) on NTFP harvesting, which is helpful for decision making in land use and resource management. The maps that are generated can also be used to zone the area for managing visitors who harvest NTFPs for commercial or recreational use to reduce the resource degradation as well as managing conflicts among stakeholders such as forest managers, local community members, and outsiders [6]. Our models and the resultant utility functions and maps are also useful for sharing knowledge among the stakeholders of different generations and gender with different backgrounds. Similar modeling can be applied to other species in other areas of the world where large number of people live near forests and have a historic dependence on the provisioning and cultural services of NTFP species [5,7]. In addition, such models can be rapidly developed without an intensive field survey, although a certain amount of surveys are necessary for model validation and for improving the estimation accuracy.

\section{Conclusions}

The knowledge of expert harvesters can be used to estimate the spatial distribution of both the habitats and harvesting sites of edible wild ferns using MCE and GIS. Using an AHP framework to determine the relative importance of landscape features, we found that harvesters considered both canopy and terrain features when estimating habitat distributions, but these features had different impacts on the three fern species. These differences were based on natural and anthropogenic factors such as riparian disturbance, snow avalanches, and land use history. In addition, some parts of the habitats that were accessible from roads were used as harvesting sites, which also differed among fern species. These differences between habitats and harvesting sites, as well as among species, are important for understanding their sustainable harvesting. Once a sufficient GIS dataset is prepared, similar knowledge-based models could easily be developed for other NTFPs for which sustainable harvesting is an important concern.

\section{Acknowledgments}

We would like to thank the inhabitants of Tadami town, particularly, Koukichi Kariya and Masanobu Saito, who shared their knowledge of gathering edible wild ferns for our study, and Isamu Nikkuni, who kindly provided the original vegetation maps. Researchers from the FFPRI supported our field survey. Kaori Suzuki inputted data from field notes and harvesters' daily records. Our thanks also go to several fellow researchers for their useful advice on the earlier draft of this study, 
e.g., Guillermo M. Pastur, CADIC Argentina, Rajesh B. Thapa, JAXA, and Satoko Kawarasaki, FFPRI. We wish to thank to two anonymous reviewers for their constructive comments and suggestions that helped us to improve the manuscript. This study was supported by the Global Environment Research Fund (E-0801) of the Ministry of the Environment, Japan, and JSPS Grants-in-Aid for Scientific Research (24310035) of The Ministry of Education, Culture, Sports, Science and Technology, Japan.

\section{Conflicts of Interest}

The authors declare no conflict of interest.

\section{References}

1. Charnley, S.; Fischer, P.A.; Jones, T.E. Integrating tradtional and local ecological knowledge into forest biodiversity conservation in the Pacific Northwest. For. Ecol. Manag. 2007, 246, 14-28.

2. Berkes, F.; Colding, J.; Folke, C. Rediscovery of traditional ecological knowledge as adaptive management. Ecol. Appl. 2000, 10, 1251-1262.

3. Trosper, R.L.; Parrotta, J.A. Introduction: The Growing Importance of Traditional Forest-Related Knowledge. In Traditional Forest-Related Knowledge: Sustaining Communities, Ecosystems and Biocultural Diversity; Parrotta, J.A., Trosper, R.L., Eds.; Springer: Berlin, Germany, 2012; Volume 12, pp. 1-36.

4. Pei, S.; Zhang, G.; Huai, H. Application of traditional knowledge in forest management: Ethnobotanical indicators of sustainable forest use. For. Ecol. Manag. 2009, 257, 2017-2021.

5. Delang, C.O. Not just minor forest products: The economic rationale for the consumption of wild food plants by subsistance farmers. Ecol. Econ. 2006, 59, 64-73.

6. Jones, T.E.; Lynch, A.K. Nontimber forest products and biodiversity management in the Pacific Northwest. For. Ecol. Manag. 2007, 246, 29-37.

7. Shackleton, C.M.; Pandey, A.K. Positioning non-timber forest products on the development agenda. For. Policy Econ. 2013, 38, 1-7.

8. Pandit, B.H.; Thapa, G.B. A tragedy of non-timber forest resources in the mountain commons of Nepal. Environ. Conserv. 2003, 30, 283-292.

9. Mutenje, M.J.; Ortmann, G.F.; Ferrer, S.R.D. Management of non-timber forestry products extraction: Local institutions, ecological knowledge and market structure in South-Eastern Zimbabwe. Ecol. Econ. 2011, 70, 454-461.

10. Ticktin, T. The ecological implication of harvesting non-timber forest products. J. Appl. Ecol. 2004, 41, 11-21.

11. Ticktin, T.; Shackleton, C. Harvesting Non-Timber Forest Products Sustainably: Opportunities and Challenges. In Non-Timber Forest Products in the Global Context; Shackleton, S., Shackleton, C., Shanley, P., Eds.; Springer: Berlin, Germany, 2011; Volume 7, pp. 149-169.

12. Stanley, D.; Voeks, R.; Short, L. Is non-timber forest product harvest sustainable in the less developed world? A systematic review of the recent economic and ecological literature. Ethnobiol. Conserv. 2012, 1, 1-39. 
13. Schreckenberg, K. Products of a managed landscape : Non-timber forest products in the parklands of the Bassila region, Benin. Glob. Ecol. Biogeogr. 2013, 8, 279-289.

14. Drew, C.A.; Perera, A.H. Expart Knowledge as a Basis for Landscape Ecological Predictive Models. In Predictive Species and Habitat Modeling in Landscape Ecology: Concepts and Applications; Drew, C.A., Wiersma, Y.F., Huettmann, F., Eds.; Springer: Berlin, Germany, 2011; pp. 229-248.

15. Yamada, K.; Elith, J.; Mccarthy, M.; Zerger, A. Eliciting and integrating expert knowledge for wildlife habitat modelling. Ecol. Model. 2003, 165, 251-264.

16. Rist, L.; Shaanker, R.U.; Milner-Gulland, E.J.; Ghazoul, J. The use of traditional ecological knowledge in forest management: An example from India. Ecol. Soc. 2010, 15, Article 3.

17. Store, R.; Kangas, J. Integrating spatial multi-criteria evaluation and expart knowledge for GIS-based habitat suitability modelling. Landsc. Urban Plann. 2001, 55, 79-93.

18. Store, R.; Jokimäki, J. A GIS-based multi-scale approach to habitat suitability modeling. Ecol. Model. 2003, 169, 1-15.

19. Phua, M.-H.; Minowa, M. A GIS-based multi-criteria decision making approach to forest conservation planning at a landscape scale: A case study in the Kinabalu Area, Sabah, Malaysia. Landsc. Urban Plann. 2005, 71, 207-222.

20. Malczewski, J. GIS-based multicriteria decision analysis: A survey of the literature. Int. J. Geogr. Inf. Sci. 2006, 20, 703-726.

21. Mendoza, A.G.; Martins, H. Multi-criteria decision analysis in natural resource management: A critical review of methods and new modelling paradigms. For. Ecol. Manag. 2006, 230, 1-22.

22. Parrotta, J.A.; Fui, L.H.; Jinlong, L.; Ramakrishnan, P.S.; Yeo-Chang, Y. Traditional forest-related knowledge and sustainable forest management in Asia. For. Ecol. Manag. 2009, 257, 1987-1988.

23. Yang, X.; Skidmore, K.A.; Melick, R.D.; Zhou, Z.; Xu, J. Mapping non-wood forest product (matsutake mushrooms) using logistic regression and a GIS expart system. Ecol. Model. 2006, 198, 208-218.

24. Ikeya, K. Spatial structure of Zenmai gathering: A case study of the mountain village in the heavy snow zone. Sci. Rep. Tohoku Univ. 7th Ser. 1988, 38, 104-118.

25. Ikeya, K. Cultural ecology of Zenmai gathering in the northeastern Japan. Sci. Rep. Tohoku Univ. 7th Ser. 2004, 53, 1-28.

26. Inoue, $T$. The transaction of wild plant use as food: The case study of wild vegetables and mushrooms in Akiyamago-district, Sakae, Nagano (in Japanese). Ecosophia 2002, 10, 77-100.

27. Saito, H. Wild edible plant gathering activities practiced at ecotones: Two contrasting case studies of villages in Japan (in Japanese with English abstract). Bull. Natl. Mus. Jpn. Hist. 2005, 123, 325-353.

28. Kawarasaki, H.S.; Sugimura, K. Estimation of frequency and locality of collection of wild mushroom and wild vegetables by internet search (in Japanese with English abstract). J. Jpn. For. Soc. 2012, 94, 95-99.

29. Matsuura, T.; Hayashi, M.; Sugimura, K.; Tanaka, N.; Miyamoto, A. Ecosystem services valuation of gathering edible wild plants/mushrooms - a case study in Tadami town, Fukushima prefecture (in Japanese with English abstract). Jpn. J. For. Plann. 2013, 47, 55-80. 
30. Saito, H. Activities of gathering wild edible plants and mushrooms by city dwellers: Analysises of its background and characteristics through quesitionnaire surveys on mountaineering club members in Iwate and Kyoto prefectures (in Japanese). For. Econ. 2005, 58, 1-16.

31. Kashimura, T. Ecological study of the natural forest vegetation in the snowy region along the lower Tadami valley. Ecol. Rev. 1968, 17, 153-170.

32. Kawano, S.; Nikkuni, I. Forest Vegetation, Flora and Fauna, and Biodiversity in Tadami-machi, Fukushima Prefecture, Honshu, Japan: Primaeval Beech and Riparian Forests, Sustainable Rich Flora and Fauna; Tadami-machi Board of Education: Fukushima, Japan, 2004.

33. Sato, T. Phenology and wintering capacity of sporophytes and gametophytes of ferns native to northern Japan. Oecologia 1982, 55, 53-61.

34. Iwatsuki, K. Ferns and Fern Allies of Japan (in Japanese with English abstract); Heibonsha Ltd.: Tokyo, Japan, 1992; p. 311.

35. Odland, A.; Naujalis, J.R.; Stapulionyte, A. Variation in the structure of Matteuccia struthiopteris populations in Lithuania. Biologija 2006, 1, 83-90.

36. Von Aderkas, P. Economic history of ostrich fern, Matteuccia struthiopteris, the edible fiddlehead. Econ. Bot. 1984, 38, 14-23.

37. Page, C.N. The taxonomy and phytogeography of bracken. Bot. J. Linn. Soc. 1976, 73, 1-34.

38. Pakeman, R.J.; Marrs, R.H. The conservation value of bracken, Pteridium aquilinum (L.) Kuhn-dominated communities in the UK, and an assessment of the ecological impact of bracken expansion or its removal. Biol. Conserv. 1992, 62, 101-114.

39. Gil da Costa, R.M.; Bastos, M.; Oliveira, P.A.; Lopes, C. Bracken-associated human and animal health hazards: Chemical, biological and pathological evidence. J. Hazard. Mater. 2012, 203-204, 1-12.

40. Hodge, W.H. Fern foods of Japan and the probrem of toxicity. Am. Fern J. 1973, 63, 77-80.

41. May, L.W. The economic uses and associated folklore of ferns and fern allies. Bot. Rev. 1978, 44, 491-528.

42. Pemberton, R.; Lee, N. Wild food plants in South Korea; market presence, new crops, and exports to the United States. Econ. Bot. 1996, 50, 57-70.

43. Hirono, I. Edible plants containing naturally occurring carcinogens in Japan. Jpn. J. Cancer Res. 1993, 84, 997-1006.

44. Kato, M. Distribution of Osmundaceae. Bull. Natl. Museum Nat. Sci. Ser. B (Bot.) 2007, 33, 81-90.

45. Kawabata, Y. Shokusei: Tadami-machi-no-shinrin-ya-sougen. In Aizu Tadami no Shizen: Shokubutsu-hen (in Japanese); Tadami-machi shishi-hensan-iinkai, Ed.; Tadami-machi town office: Fukushima, Japan, 2001; pp. 52-71.

46. Rennó, D.G.; Nobre, D.A.; Cuartas, A.L.; Soares, V.J.; Hodnett, G.M.; Tomasella, J.; Waterloo, J.M. HAND, a new terrain descriptor using SRTM-DEM: Mapping terra-firme rainforest environment in Amazonia. Rem. Sens. Environ. 2008, 112, 3469-3481.

47. Kangas, S.A.; Horne, P.; Leskinen, P. Measuring the value of information in multicriteria decisionmaking. For. Sci. 2010, 56, 558-566.

48. Saaty, T.L. The Analytic Hierarchy Process; McGraw-Hill: New York, NY, USA, 1980; p. 287. 
49. Yalcin, A. GIS-based landslide susceptibility mapping using analytical hierarchy process and bivariate statistics in Ardesen (Turkey): Comparisons of results and confirmations. Catena 2008, $72,1-12$.

50. Estoque, R.C. Analytic Hierarchy Process in Geospatial Analysis. In Progress in Geospatial Analysis; Murayama, Y., Ed.; Springer: Berlin, Germany, 2012; pp. 157-181.

51. Pukkala, T.; Kangas, J. A heuristic optimization method for forest planning and decision making. Scand. J. For. Res. 1993, 8, 560-570.

52. Beyer, H.L. Geospatial Modelling Environment (Version: 0.7.2.1). Available online: http://www.spatialecology.com/gme (accessed on 11 October 2013).

53. Hirzel, A.H.; Guisan, A. Which is the optimal sampling strategy for habitat suitability modelling. Ecol. Model. 2002, 157, 331-341.

54. Fielding, H.A.; Bell, F.J. A review of methods for the assessment of prediction errors in conservation presence/absence models. Environ. Conserv. 1997, 24, 38-49.

55. Manel, S.; Williams, C.H.; Ormerod, J.S. Evaluating presence-absence models in ecology: The need to account for prevalence. J. Appl. Ecol. 2001, 38, 921-931.

56. Freeman, E.; Moisen, G. A comparison of the performance of threshold criteria for binary classification in terms of predicted prevalence and kappa. Ecol. Model. 2008, 217, 48-58.

57. Pearce, J.; Ferrier, S. Evaluating the predictive performance of habitat models developed using logistic regression. Ecol. Model. 2000, 133, 225-245.

58. Mizuno, N. Sansai/Kinomi. Yama-Kei Pocket Guide 4 (in Japanese); Yama-kei Publishers co.,Ltd.: Tokyo, Japan, 1999; p. 281.

59. Thayer, S. Nature's Garden: A Guide to Identifying, Harvesting, and Preparing Edible Wild Plants; Forager's Harvest Press: Birchwood, OH, USA, 2006; p. 360.

60. Ohsawa, A. Fukushima-no-sansai-to-kinoko (in Japanese); Rekishi-Shunju-Shuppan Co.Ltd.: Fukushima, Japan, 2001; p. 184.

61. Suzuki, W.; Osumi, K.; Masaki, T.; Takahashi, K.; Daimaru, H.; Hoshizaki, K. Disturbance regimes and community structures of a riparian and an adjacent terrace stand in the Kanumazawa. For. Ecol. Manag. 2002, 157, 285-301.

62. Kawanishi, M.; Sakio, H.; Kubo, M.; Shimano, K.; Ohno, K. Effect of micro-landforms on forest vegetation differentiation and life-form diversity in the Chichibu Mountains, Kanto District, Japan. Veg. Sci. 2006, 23, 13-24.

63. Shimada, Y. Ecology of bracken (Pteridium aquilinum (L.) Kuhn): Dynamics of bracken population in native grassland (in Japanese with English abstract). Weed Res. 1962, 1, 70-77.

64. Higuchi, K.; Sato, A.; Kato, R.; Shimoda, H. Studies on the weed-vegetation at the early stage of plantation (I): Vegetative transition on Cryptomeria japonica forests planted in every year (in Japanese with English abstract). J. Jpn. For. Soc. 1975, 57, 346-350.

65. Sugiura, T. Warabi (Pteridium aquilinum) and Sugi (Cryptomeria japonica) under intensive agroforestry (in Japanese). J. Jpn. For. Soc. 1988, 70, 163-171.

66. Aiura, H. Erosive phenomenon in heavy snow mountainous regions in Japan. J. For. Res. 2002, 7 , $57-66$.

67. Shimokawa, K. Geomorphic study of avalanche chute in the upper drainage basin of the Tadami River (in Japanese with English abstract). Geogr. Rev. Jpn. 1980, 53, 171-188. 
68. Nagamatsu, D.; Miura, O. Soil disturbance regime in relation to micro-scale landforms and its effects on vegetation structure in a hilly area in Japan. Plant Ecol. 1997, 133, 191-200.

69. Sugimura, K.; Okitsu, S. Disturibution of bryophyte, pteridophyte, and flowering plant species in relation to the micro-landform in the Cryptomeria japonica and Chamaesyparis obtusa plantations of Mt. Tsukuba, central Japan (in Japanese with English abstract). Veg. Sci. 2009, 26, $33-48$.

70. Hiruma, A.; Hukusima, T. Geographical differences in the habitat of forb species occuring in Japanese beech (Fagus crenata) forest zone (in Japanese with English abstract). Veg. Sci. 2004, $21,39-50$.

71. Osumi, K.; Ikeda, S.; Okamoto, T. Vegetation patterns and their dependency on site conditions in the pre-industrial landscape of north-eastern Japan. Ecol. Res. 2003, 18, 753-765.

72. Landi, M.; Angiolini, G. Ecological responses of Osmunda regalis to forest canopy cover and grazing. Am. Fern J. 2010, 100, 137-147.

73. Albers, H.; Robinson, E. A review of the spatial economics of non-timber forest product extraction: Implications for policy. Ecol. Econ. 2013, 92, 87-95.

74. Rist, L.; Shanley, P.; Sunderland, T.; Sheil, D.; Ndoye, O.; Liswanti, N.; Tieguhong, J. The impacts of selective logging on non-timber forest products of livelihood importance. For. Ecol. Manag. 2012, 268, 57-69.

75. Guariguata, M.; García-Fernández, C. Compatibility of timber and non-timber forest product management in natural tropical forests: Perspectives, challenges, and opportunities. For. Ecol. Manag. 2010, 259, 237-245.

(C) 2013 by the authors; licensee MDPI, Basel, Switzerland. This article is an open access article distributed under the terms and conditions of the Creative Commons Attribution license (http://creativecommons.org/licenses/by/3.0/). 